\title{
Study on the Optimization of Perishable Goods Logistics Network Based on the Particle Swarm Algorithms
}

\author{
Ruiwei Liang \\ Hunan Modern Logistics College \\ Changsha, China 410131
}

\author{
Shijun Yuan* \\ Hunan Modern Logistics College \\ Changsha, China410131 \\ *Corresponding Author
}

\begin{abstract}
During the purchase and transport planning of perishable goods, what we should consider shall not only include purchase cost, transport cost, but also time cost. In most cases, time cost is even a decisive factor. In this article, authors create a mathematical model on the basis of particle swarm algorithms in response to a kind of typical perishable goods purchase, discussing a scheme to optimize the perishable goods logistics network.
\end{abstract} factor

Keywords_perishable goods; particle swarm algorithm; time

\section{INTRODUCTION}

In real life, the value of some goods drops gradually with the time going, such goods are called perishable goods like garment, electronic elements and so on, which have higher time validity, whose value generally decreases rapidly with the coming of new products; fresh goods as vegetables, fruits and meat are difficult to keep fresh for a long time and will need high costs to do the same, which have time costs. Therefore, during the purchase and transport planning of perishable goods, we should take not only purchase costs, transport costs but also time costs into consideration. In most cases, the time costs even become a decisive factor.

Han Shilian et al [1] gives definition of clients' time for waiting and target planning principle, creating a linear planning model on how to optimize multi-goal logistics distribution paths with time window. And three goals which are conflicting with each other are considered including the minimum transport costs, the shortest time for transport and the shortest time for clients to wait.

Based on the vehicle distribution planning model with time window, Wang Haili, et al [2] create a cold storage distribution model related to perishable goods with the total costs of refrigeration costs, fixed vehicle costs and transport costs as target function. As far as the algorithm design, a saving algorithm is created on the basis of local search.

Chen Jun, et al [3] analyze that all members take the expected demand of other members as an actual one among purchase league members due to unbalanced information. Considering the characteristics of perishable goods purchase and transport, the authors propose special binding conditions related to price adjustment and create a league expected profits model, finally simulating it with figures.

According to characteristics of emergency logistics, Wang Haijun et al [4] adopt simulated annealing algorithm to study the emergency logistics vehicle scheduling, with actual cases provided, the simulated annealing algorithm is compared with immune algorithm, which prove the feasibility and overall optimum of the simulated annealing algorithm used to optimize vehicle driving ways.

\section{Solutions Proposed TO OPtIMIZE PERISHABLE GOODS LOGISTICS NETWORK}

Suppose an enterprise purchases $J$ materials (which belong to perishable goods) from $I$ suppliers, and one of $K$ transfer stations delivers the materials to the buyer, the value of each material declines at the speed of $a_{j}$ as unit time; the buyer needs to determine suppliers for each material and transfer station in order to minimize the purchase costs, transport costs and the sum of materials as per the time costs. Exhaustive method can be used to get the optimal solution for the project. There are $I^{J} * K$ plans to be compared, whose complexity takes on exponential growth compared to suppliers and raw materials purchased, and multiple increase compared to the transfer station number.

\section{CREATING A Model to OPtIMIZE THE PERISHABLE GoOds LOGISTICS NETWORK ON THE BASIS OF PARTICLE SWARM ALGORITHMS}

Before the mathematical model is created, according to characteristics of particle swarm algorithms, in order to make it easy for modeling and computing optimization, main control variables and parameters set are given as follows:

$$
C 0_{i j} \text { : Unit price for } j \text { materials the buyer purchases }
$$
from supplier $i$ 
$Q_{j}$ : Number of material J the buyer needs to purchase;

$C 1_{i j k}$ : Transport unit price for $\mathrm{j}$ materials purchased from supplier $i$ and delivered to the transfer station $k$.

$C 2_{j k}$ : Transport unit price to transport $\mathrm{j}$ materials to the buyer from transport station $\mathrm{K}$;

$T_{i k}$ : Transport time from enterprise $i$ to transfer station $j$, all materials are the same in time needed;

$T_{j}$ : The time needed to deliver $\mathrm{J}$ material to the given transfer station;

$T_{k}$ : The time to deliver materials to the buyer from transfer station $k$;

$a_{j}$ : Percentage of the material value loss in unit time in the total material value;

$S_{i j}$ : Whether material $i$ is purchased at supplier $i$ if yes, $S_{i j}=1 \underset{\text { or }}{ } S_{i j}=0$

$D_{k}$ : Whether the transfer station $k$ is selected for this purchase plan, if yes, $D_{k}=1$ or $D_{k}=0$

Where, $i$ : supplier index $(i=1,2, \cdots, I), j$ : raw material index of the buyer $(j=1,2, \cdots, J)$, k: transfer station index $(k=1,2, \cdots, K)$.

With the above parameters given, it is time to create a target function for total costs of the logistics network model, which consist of four parts, namely 1 st transport costs, 2nd transport costs, transport time costs (ignoring transfer costs and time):

$$
\begin{aligned}
& \min f=\sum_{j=1}^{J} \sum_{i=1}^{I} C 0_{i j} * S_{i j} * Q_{j}+\sum_{k=1}^{K} \sum_{j=1}^{J} \sum_{i=1}^{I} Q_{j} * C 1_{i j k} * S_{i j} * D_{k} \\
& +\sum_{k=1}^{K} \sum_{j=1}^{J} Q_{j} * C 2_{i j} * D_{k}+\sum_{j=1}^{j}\left\{\left[\max \left(T_{j}\right)+\sum_{k=1}^{K} T_{k} * D_{k}\right] * a_{j} * \sum_{i=1}^{I} S_{i j} * Q_{j} * C 0_{i j}\right\}
\end{aligned}
$$

Constraint conditions:

$$
\text { s.t }\left\{\begin{array}{l}
S_{i j}=\quad 0 \text { or } 1 \\
\sum_{i=1}^{I} S i j=1 \\
D_{k}=0 \text { or } 1 \\
\sum_{k=1}^{K} D_{k}=1 \\
T_{j}=\sum_{k=1}^{K} \sum_{i=1}^{I} T_{i k} * S_{i j} * D_{k}
\end{array}\right.
$$

\section{Algorithm Design to Optimize the Perishable} GOODS LOGISTICS NETWORK

In this model, $C 0_{i j}, C 1_{i j k}, C 2_{j k}, T_{i k}, T_{k}, Q_{j}, a_{j}$ are given variables, $T_{j}$ is intermediate variable, only $S_{i j}$ and $D_{k}$ are decisive variables, which are 0,1 variables, totaling $(0,1)$ decisive variables: $I^{*} J+K$, besides, which need to meet two binding conditions : $\sum_{i=1}^{I} S_{i j}=1 \quad \sum_{k=1}^{K} D_{k}=1$ Namely, $i^{*} j+k$ decisive variables $(0,1)$ have feasible solution as $(J+1) 1$, yet other decisive variables are 0 . Of which, the first $J_{1}$ will determine suppliers for each raw material, and the final 1 is to confirm the selected transfer station.

Initially the particle swarm algorithm is used to solve continuous optimizations, and binary system particle swarm algorithm shall be used for 0,1 discrete optimization. However, due to binding conditions for this model, the continuous particle swarm algorithm can be adjusted to solve the problem, which will become much more convenient. Specific procedures to solve the problem by the continuous particle swarm algorithm include:

- Initially, each particle has $I^{*} J+K$ dimensions, adopting random value within $(0,1)$, which is divided into two matrixes $\mathrm{J}$ line I row plus 1 line $\mathrm{K}$ row, just initialize the speed as per the same method;

- calculate the particle's adaptive value, set the max element in each line to be 1 , and other elements 0 , and then get the adaptive value as per (5.1);

- find the particle most excellent in history and group;

- renew the particle's position;

- renew the particle's speed;

- get the particle's adaptive value after renewal as per step 2), and renew the particle most excellent in history and group; 
- judge whether it meets conditions to terminate, if yes, terminate calculation and output, or move to step 4.

In this method, special treatments are made to calculate the particle's most excellent value so that each particle meets binding condition to solve.

\section{Cases About Optimizing Perishable Goods LOGISTICS NETWORK ON THE BASIS OF PARTICLE SWARM ALGORITHM}

Suppose, an electronic factory needs to purchase electronic elements A, B, C from three suppliers $S_{1}, S_{2}, S_{3}$, which will be transferred at one of the three transfer stations $D_{1}, D_{2}, D_{3}$, then the materials will be delivered to factory E. The material loss rate with the time going is $a_{j}=0.25 \%$ / $\mathrm{d}$, and other data are given as follows in "Table I", "Table II", "Table III", "Table IV":

TABLE I. MATERIALS DEMAND (TON)

\begin{tabular}{cccccc}
\hline Materials & & A & & B & C \\
\hline Demand & 15 & & 12 & 18 & \\
\hline
\end{tabular}

TABLE II. 2ND TRANSPORT COSTS RATE AND TIME (TEN THOUSAND YUAN/T/D)

\begin{tabular}{lllr}
\hline & D1 & D2 & D3 \\
\hline $\mathrm{E}$ & $1.5(20)$ & $1.8(15)$ & $1.6(10)$ \\
\hline
\end{tabular}

TABLE III. 1ST TRANSPORT COSTS RATE AND TIME (TEN THOUSAND YUAN/T/D)

\begin{tabular}{llll} 
& \multicolumn{1}{c}{ D1 } & \multicolumn{1}{c}{ D2 } & \multicolumn{1}{c}{ D3 } \\
\hline S1 & $0.65(7)$ & $1.25(10)$ & $1.65(14)$ \\
S2 & $0.68(8)$ & $1.20(8)$ & $1.55(13)$ \\
S3 & $0.60(7)$ & $1.25(10)$ & $1.60(14)$ \\
\hline
\end{tabular}

TABLE IV. Material Purchase Price (Ten Thousand YUAN/T)

\begin{tabular}{|c|c|c|c|}
\hline & $\mathbf{A}$ & B & $\bar{C}$ \\
\hline $\mathrm{S} 1$ & 14.6 & 18.2 & 12.4 \\
\hline $\mathrm{S} 2$ & 14.4 & 18.4 & 12.6 \\
\hline $\mathrm{S} 2$ & 14.5 & 18.3 & 12.2 \\
\hline
\end{tabular}

The buyer needs to make a purchase plan to purchase three raw materials from three suppliers and select a proper transfer station to minimize the purchase costs, transport costs and time loss. In this article, particle swarm algorithm will be used to calculate the model mentioned above with Matlable language for programming, the problem is solved finally. In this case, the dimension of each particle is $I * J+K=3 * 3+3=12$, suppose the group scale is 20 , iteration: 500 , it is calculated by three particle swarm algorithms in 30 experiments, and the convergence-optimal mean iteration times are given in "Table V", and the optimal plans are given as "Table VI" and "Table VII".

TABLE V. CONVERgence SpeEds COMPARISOn Between Three PARTICLE SWARM ALGORITHMS

\begin{tabular}{lll}
\hline $\begin{array}{c}\text { Optimization } \\
\text { Method }\end{array}$ & Convergence Success & Mean Iteration Times \\
\hline PSO-LW & $100 \%$ & 63 \\
PSO-PC & $100 \%$ & 52 \\
PSO-SC & $100 \%$ & 58 \\
\hline
\end{tabular}

Seen from "Table V", three particle swarm algorithms all have stable convergences till the overall optimal solution, during 30 experiments, the average iteration times of two improved particle swarm algorithms need less average iteration times needed by standard particle swarm algorithms.

TABLE VI. OPTIMAL PURChASE

\begin{tabular}{llll}
\hline Sij & $\mathbf{j}=\mathbf{1}$ & $\mathbf{j = 2}$ & $\mathbf{j = 3}$ \\
\hline $\mathrm{i}=1$ & 0 & 1 & 0 \\
$\mathrm{i}=2$ & 0 & 0 & 0 \\
$\mathrm{i}=3$ & 1 & 0 & 1 \\
\hline
\end{tabular}

TABLE VII. OPTIMAL TRANSFER PLAN

\begin{tabular}{llll}
\hline $\mathbf{D k}$ & $\mathbf{k}=\mathbf{1}$ & $\mathbf{k}=\mathbf{2}$ & $\mathbf{k}=\mathbf{3}$ \\
\hline 0 & 1 & 0 \\
\hline
\end{tabular}

Namely material A will be purchased at three suppliers; material $\mathrm{B}$ will be purchased at a supplier; material $\mathrm{C}$ will be purchased at three suppliers; and the transfer station 2 will be selected for materials transfer.

According to the plan, the purchase costs will be $6,525,000$ yuan

Transport costs: 562,500 yuan

Material loss costs with the time going: 358,875 yuan

Total costs: $7,476,375$ yuan

The exhaustive method is used: 81 plans and the result has the same result as what got by the optimal plan.

\section{CONCLUSION}

According to characteristics of perishable goods, this article creates an optimization model on the basis of particle swarm algorithm, and discusses the particle swarm algorithm can work well to optimize the perishable goods logistics network via empirical studies.

\section{REFERENCES}

[1] Han Shilian, Goal Planning Model for Time Window-based Multipurpose Distribution Lines Selections, Vol.27, 2008, 1st Period: 44 46. (in Chinese) 
[2] Wang Haili, Wang Yong, Zeng Yongzhang, Refrigerated Truck for Time Window-based Perishable Foods Distribution, Industrial Engineering Journal, Vol.11, No. 3:127-130. (in Chinese)

[3] Chen Jun, Dan Bin, Analyzing Decision Making on Joint Purchase of Perishable Goods, Industrial Engineering Journal, Vol. 110 No .3 May 2007:19-22. (in Chinese) 